\title{
AN OUTBREAK OF TRI-ORTHO-CRESYL PHOSPHATE (T.O.C.P.) POISONING IN DURBAN
}

\author{
BY \\ MERVYN SUSSER AND ZENA STEIN \\ From King Edward VIII Hospital, Durban, South Africa \\ (RECEIVED FOR PUBLICATION AUGUST 30, 1956)
}

Tri-ortho-cresyl phosphate (T.O.C.P.) is an organic phosphorus compound commonly used in industry as a plasticizer, and is so used in the manufacture of lacquers, dopes, synthetic fabrics, and synthetic lignin resin; it is used as a water-proofing agent in textile manufacture. It is said to be an excellent grinding medium for pigments; it is also used in making polyvinyl chloride sheeting and for the recovery of phenol residues from gas-plant effluents. The vapour pressure of T.O.C.P. is 0.01 $\mathrm{mm}$. $\mathrm{Hg}$ at $20^{\circ} \mathrm{C}$. Its solubility in water is less than $0.002 \%$ at $86^{\circ} \mathrm{C}$. and even less at lower temperatures, but T.O.C.P. is readily soluble in all common organic solvents, including alcohol, and in most vegetable oils. It is chemically stable and resists hydrolysis.

\section{Previous Outbreaks}

Eight previous outbreaks of T.O.C.P. poisoning have been reported. The first was by Lorot (1899) when six cases occurred among patients who were given a phosphocreosote cough mixture which contained T.O.C.P.

The great mass of recorded cases occurred in the United States in 1930 during prohibition. Some $10,000-15,000$ people were poisoned by a popular substitute for alcohol called "ginger jake". It has never been discovered precisely why T.O.C.P. was used in abstracting the Jamaica root that flavoured this ginger extract (Smith, Elvove, and Frazier, 1930; Smith and Elvove, 1931; Smith, Engel, and Stohlman, 1932; Burley, 1930, 1932; Zeligs, 1938; Aring, 1942). Many of these patients were hard drinkers or vagrants in a period of economic depression.

In 1931 several hundred women in Europe were poisoned by T.O.C.P. combined in an apiol pill and taken as an abortifacient. The T.O.C.P. was presumably included as an additional stimulus to abortion (Ter Braak, 1931).
The next report came from Durban in 1938. Thirty-one men, women, and children, including whites, Africans, and Indians, were affected by a " mystery disease ". A further 27 cases then occurred on the French ship Jean L.D., practically rendering her helpless in the Bay of Biscay. This ship had called at Durban. The source was traced to drums of cooking oil contaminated by previous use for T.O.C.P. (Drummond, 1938).

Walthard (1946) described an outbreak in 1940 when 80 men of the Swiss army were poisoned; T.O.C.P. had been mistakenly used as cooking oil.

During the war, when fats were in extremely short supply in Germany, several factory workers took T.O.C.P. home and were poisoned when they used it as a fat substitute in cooking (Humpe, 1942).

Hunter, Perry, and Evans (1944) described three cases in England in 1942. Three men, who worked over a tank containing T.O.C.P. in the closest black-out conditions, were apparently poisoned by vaporization of the T.O.C.P.

Finally Hotston (1946) collected several cases which appeared sporadically in Liverpool; the source was again traced to contaminated cooking oil.

\section{A Recent Outbreak in South Africa}

An outbreak occurred in Durban, South Africa, in 1955, involving 11 African patients whose ages ranged from 7 to 46 years.

In addition to the 11 patients, we had the opportunity of examining four others, the mother, father, son, and daughter of one family who had all been poisoned in Durban in 1937-38, 18 years before. This was a white family whose ages in 1955 ranged from 28 to 55 .

In July, 1955, D. N. and G. N., a married couple, and R. H., who lived in the same shack, were admitted to King Edward VIII Hospital, Durban. The 14-month-old daughter of $D$. N. and G. N. was the only other occupant of the shack and she 
did not fall ill. R. H. went to a different ward from his room-mates and the connexion between him and the others was not known at that time. A diagnosis of radiculo-myelitis was made in the case of R. H., while D. N. and G. N. were considered to have polyneuritis of unknown aetiology.

D. N. was employed at a local paint factory. From his friends he heard that E. K., a fellowworker who had been on the same night shift with him, had fallen ill with a similar complaint to his and at about the same time. E. K. never came to hospital but we visited him and he is included in the series.

D. N.'s shack was unoccupied from July until the beginning of October, when relatives moved in. One month later all the new occupants, except a month-old baby, contracted the illness. This group comprised two women, two men, and three children.

The only connexion between D. N. and E. K. was the paint factory. The rest of the patients all occupied D. N.'s home, using the same premises and some of the same utensils and water containers but not the same food.

Apart from the convincing clinical picture (confirmed by Dr. J. Drummond, who had observed and reported on the 1937-38 Durban outbreak), the connexion with T.O.C.P. was made when we learned that this compound was freely used without special precautions in the paint factory at which D. N. and E. K. were employed. No evidence of exposure to any other known poison, including lead, was found.

From this point, investigation became difficult. For obvious reasons, Africans in urban locations have little trust in whites, especially whites who are apparently connected with authority. In this case, suspicion was the more acute because, as was discovered later, not only did D. N. brew illicit liquor for sale, but without permission he and E. K. had removed certain drums from the paint factory. D. N.'s family used these drums for collecting water from the communal tap in the location, for storing water, and for brewing liquor. Water used by the households during July and October was held in these drums. The drums commonly carried T.O.C.P. at the factory from whence they had been removed shortly before D. N. and his household and E. K. fell ill. Tri-ortho-cresyl phosphate was not isolated from the one drum that was found in D. N.'s shack. (It was not isolated from an oil-containing drum at the first attempt in the 1937-38 Durban outbreak.)

The investigation of E. K.'s case could not be undertaken in detail and only limited interviews were held. We are at a loss to explain the escape of the rest of E.K.'s family or indeed the way in which he was poisoned. There was no doubt about the clinical picture in the 11 affected persons, however, and the circumstantial connexion with T.O.C.P. was strong enough evidence that it was the cause of the outbreak.

Mode of Absorption.-Outbreaks of T.O.C.P. poisoning have occurred in several different ways. Both ingestion of the compound-made up in medicaments, or dissolved in alcohol or in vegetable oils-and inhalation have previously occurred. Tri-ortho-cresyl phosphate can also be absorbed through the skin; Hodge and Sterner (1943) on the basis of their experiments with tracers considered this a definite hazard. Although the solubility of T.O.C.P. in water is very low, ingestion with contaminated water in the present episode was probable. Solution in alcohol is unlikely. First, D. N. sold the liquor he brewed and there were no cases amongst his regular customers; secondly, the three children of 11,9 , and 7 years and an adult male, who was an abstainer, all contracted the illness. Hence it must be presumed that the poison was not in the drum used for brewing but in that used for water.

Cooking utensils had been removed and could not be tested. The suspected drums were used for water storage and it seems possible that, despite the low solubility of T.O.C.P., sufficient poison could have been ingested with the water either in solution or in suspension to account for the outbreak. (Cooking in the drums, if this had been the case, would greatly increase the solubility.) This hypothesis compares with the conclusions of Hunter et al. (1944) that in spite of the known low vapour pressure of T.O.C.P. poisoning by evaporation did occur in their three cases.

Individual Susceptibility.-Some clinicians report that the severity of the lesion does not appear to be proportional to dosage and it has been suggested that individual susceptibility varies, as the susceptibility of different species certainly does. However, Burley (1932) considered that in his patients dose and effect were related and this agreed with experimental findings. Only a 14-month-old baby in the first group of cases and a 1-month-old baby in the second group escaped poisoning. Young chicks appear to be resistant to the related compound D.F.P. (di-isopropyl-fluorophosphonate) and similarly the babies who escaped poisoning in the present series may have been resistant to T.O.C.P. Perhaps the infant resists demyelination because the long tracts of the spinal cord are not completely myelinated. On the other hand, the babies were to some extent fed separately and may have ingested less water. 
TABLE

SYMPTOMS AND SIGNS IN INDIVIDUAL PATIENTS IN AN OUTBREAK OF T.O.C.P. POISONING

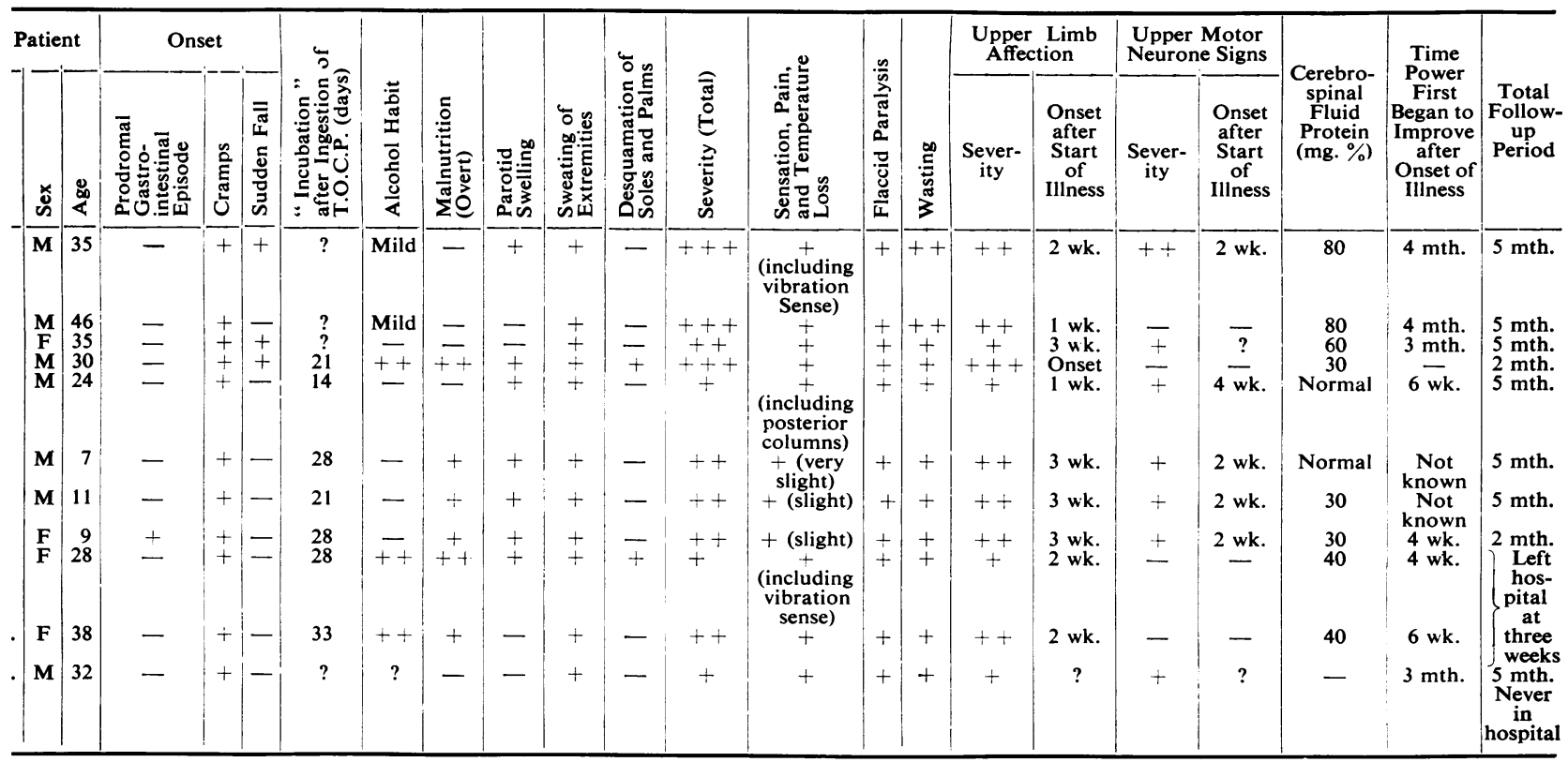

(Patients 1, 2, 3 and 11 were first affected in July, the remainder in November, 1955)

Socio-medical Aspects.-At the source of the present outbreak, the paint factory, T.O.C.P. was freely used and available without any understanding of its toxic properties, although the hazards of using T.O.C.P. without adequate precautions can be very grave. In at least two of the previously reported outbreaks, chance contamination of oil containers was responsible.

It was not possible to relate the first group of cases to a common origin. More emphasis on the family and the occupational and social background of the patients might have led to earlier recognition of the syndrome and its epidemic nature. The seven later cases might then have been prevented.

The economic hardship to the family can scarcely be exaggerated. The disease involved all the wageearners and they are all likely to have had the greatest difficulty in re-establishing themselves in manual labour, almost the only occupation open to them. With the limited resources of an African family after such a set-back rehabilitation is a major problem.

Case Reports of Present Outbreak.-The symptoms and signs of each case are summarized in the Table.

Case 1.-R. H., a man of 35 years, was admitted to hospital on July 15,1955 . Two weeks before admission he fell to the ground suddenly. After this he had difficulty in keeping his balance and noticed cramps in the calves followed by weakness in the limbs. On admission there was complete flaccid paralysis below the ankles, weakness extending up to the hips, and some weakness of the hand grip. Although brisk knee reflexes were found, ankle jerks and plantar responses were absent. Below the knees there was stocking anaesthesia for pain, temperature, light touch, and vibration sense, and hypoaesthesia above the knees as far as the umbilicus. There was very little sensory loss in the hands. The feet were cold and sweating and both parotid glands were diffusely enlarged. After two weeks in hospital a brisk knee jerk with an increase in tone of the quadriceps was detected but complete flaccid paralysis persisted from the ankles down. Gradually, weakness at the wrist increased and the muscles of the calves, the feet, and the intrinsic muscles of the hands wasted away. After about six weeks some hyperaesthesia of the soles appeared, with lessening of the extent of the sensory loss, and four months after admission sensation was almost normal. When last seen by us, five months after admission, there was only moderate improvement in power of the hands, hips, and knees, while complete foot drop persisted. The knee jerk was very brisk and stimulation of the soles produced a total withdrawal of the limb, although the toes and feet were still too weak to show any response. The feet were still sweating but the parotid swelling was gradually subsiding.

Case 2.-D. N., aged 46 years, was one of the men employed in the paint factory from which the poison was presumed to have come. He was admitted to hospital on July 18, 1955, with a history of general weakness, 
cramps in the legs, pins and needles, and numbness in the feet and hands for the preceding eight days. He had had difficulty in walking for the five days before admission. On examination, at the ankle power was much reduced, at the knee less so. Some weakness of the small muscles of the hands was found, especially on the right side. Ankle and plantar responses were not obtained. There was anaesthesia distal to the wrists and ankles and hypoaesthesia between knees and ankles. The feet were cold and sweating. There was no parotid swelling.

After two months in hospital the upper limb affection had progressed, so that by then there was complete wrist drop on the right and much weakness on the left. All the intrinsic muscles of the hands were without power and markedly wasted. In the lower limb there was a complete flaccid paralysis below the ankles and weakness extending as far as the hip. Wasting was most marked over the anterior tibial compartment and the vasti. Calf and thigh muscles were tender to pressure, but sensation was otherwise normal. The palms and soles were always cold and moist. Reflexes were normal and equal in the upper limbs, absent at the ankles, and exaggerated at the knees. There was no plantar response at all.

After five months there was a slight increase in power in the proximal muscles of the lower limb.

Case 3.-G. N., the wife of D. N. and the sister of R. H., a woman of 35 , was admitted to hospital on July 17,1955 . Ten days earlier, she had suddenly fallen to the ground, and had suffered thereafter from painful cramps in the calves and increasing difficulty in walking. On admission, she was ataxic and had bilateral foot drop. There was no power at all below the ankles, though movements at the hips, knees, and in the upper extremities were normal. The knee jerks were brisk, but no reflexes could be obtained at the ankle and there was no plantar response. There was hypoaesthesia below the calves and anaesthesia of the sole.

After two weeks in hospital, weakness of the hands and wrists was noticed, with hypoalgesia of the thenar borders.

Three months after admission, there was still no power below the ankles, movements at the hip and knee were weaker than average and muscles of the wrist and hand were uniformly weak. The deep reflexes, however, had become exaggerated and the finger flexor test was positive. Ankle jerks were still unobtainable and there was no plantar response. The intrinsic muscles of the hands and of the calf muscles were wasted. The calves were tender to pressure and the palms and soles were sweating. No parotid swelling was observed at any stage.

Case 4.-A. D., a man of 30 years, was a fairly heavy grinker. In the week preceding his admission to hospital, on November 17, 1955, he had had a sudden fall after a drinking bout, followed by cramps in the calves, weakness of the limbs, and a difficulty in keeping his balance. He had also noticed that his face was swollen shortly before admission. On examination, he was hyperpigmented, and had cheilosis and an atrophic, stripped tongue. Both parotids were swollen but not tender. His walk was ataxic and stamping; the extremities were cold and sweating profusely. There was Rombergism, and loss of pain and temperature sense distal to the wrists and ankles. The muscles of the hip joint and of the knee were weak; at the ankles there was a complete flaccid paralysis. Already, at the time of admission, there was weakness at the elbow and no power at the wrist or in the hands. Ankle and plantar reflexes were unobtainable and all other deep reflexes were depressed. We followed up this patient for two months. No improvement had begun by the end of that time nor were there yet any signs of increased reflexes or tone at the knees. Dr. F. J. Davidson reported that after five months he was still paralysed but showed signs of increased tone in the lower limbs. This was the most severely affected patient of our series.

Case 5.-M. M., a young man of 24 , was one of the milder cases. After preliminary cramps he found difficulty in walking because he could not lift up his feet. On admission on November 15, 1955, he had bilateral swelling of the parotids and complete foot drop. The muscles of the knees were also weak. There was a stocking anaesthesia below the knees, with loss of position sense and vibration sense and Rombergism. The toes were cold and moist. Position and vibration sense returned in a few days, but weakness of the hands began in the third week. At this stage, too, the knee jerks became markedly increased. Later, the biceps, triceps, supinator, and knee jerks were increased and the finger flexor test was positive on the right. Complete loss of power of the small muscles of the hands with marked wasting followed. No movements were yet possible at the ankles, although the quadriceps and hamstrings were recovering function. A slight hypoaesthesia of the soles and toes were the only remaining signs of sensory loss. Dr. Davidson reported that five months after admission M. M. showed signs of increased tone in the lower limbs.

Case 6.-D. M., a 7-year-old boy, was admitted on November 15, 1955. He had complained of cramps in the calves before admission. He was moderately affected, presenting with parotid swelling, a flaccid paralysis below the ankles, and slight sensory loss. Two weeks after admission he was found to have increased knee, triceps, biceps, and supinator reflexes. At three weeks his arms and hands became so weak that he had to be fed and the muscles of the hands and legs began to waste. He showed no improvement after six weeks in hospital except that the sensory loss had practically disappeared. The reflexes were still markedly exaggerated at the knee, triceps, biceps, and supinator tendons, and there was severe wasting of the anterior tibial muscles, the calf muscles and the peronei, also the intrinsic muscles of the hands. Five months after admission Dr. Davidson found the hyperreflexia and wasting to be still prominent.

Case 7.-E. M., the 11-year-old brother of D. M., was admitted on November 15, 1955, with symptoms and signs almost identical with those of D. M., including the parotid swelling. E. M. also developed hyperreflexia (save for the absent ankle jerks, as in his brother's case) after two weeks and marked weakness of the hands 
after three weeks. Six weeks after admission he had lost all power in the intrinsic muscles of the hands, and wasting of these muscles and those of the lower limbs became apparent. Five months after admission Dr. Davidson found that there was still weakness of the affected muscles, hyperreflexia, and wasting.

Case 8.-El. M., the 9-year-old sister of D. M. and E. M., was affected in the same way as her brothers with parotid swelling and loss of power in the lower limbs on admission, on November 15, 1955, followed by hyperreflexia, again excluding the ankle jerk which was unobtainable in the third week. Loss of power and wasting in the intrinsic muscles of the hand was obvious by the fourth week. This little girl had an episode of vomiting and abdominal pain two weeks before admission, the only reported incident of the kind in this series and it may or may not have been related to ingestion of the poison.

Case 9.-S. H., aged 38 years, the mother of D. M., E. M., and El. M., and sister of R. H., gave a history of mild cramps in the calves preceding admission on November 16, 1955. She had had no fall, and there was no parotid enlargement. Her 1-month-old baby was breast-fed up to the time of admission. S. H. was, according to her relatives, a heavy drinker, and there were some signs of malnutrition. On admission she had extreme weakness at the knees and flaccid paralysis at the ankles. Hypoaesthesia was found below the ankles, most marked on the soles. After two weeks in hospital the upper limbs became affected, with loss of power in the hands. S. H. then refused further treatment and left hospital. We saw her at home six weeks after admission, when some improvement in power was noted, but the wasting and weakness of hands and legs was still marked.

Case 10.-A. N., a woman of 28 years, a heavy drinker and a constant visitor at the affected home, was admitted on November 16, 1955. She had bilateral swelling of the parotids, flaccid paralysis of the muscles at the ankle joints, and weakness of the muscles at the hip and knee. There was hypoaesthesia in a stocking distribution below the knees. Paralysis of the hands developed in the second week, at which point this patient also insisted on leaving hospital. When last seen in her home, six weeks after admission, the lower limbs had recovered some movement, the sensory loss had gone, and the parotid swelling was smaller. The knee reflexes and those of the biceps, triceps, and supinator tendons were exaggerated, and wasting of the hand and calf muscles was severe.

Case 11.-E. K., a man of 32, was first seen at his home on November 23, 1955, four months after he had become disabled by his disease. He refused admission to hospital on religious grounds. His illness had begun with calf pain and unsteadiness of the feet and soon after his hands began to feel weak. He had never noticed any parotid swelling. At the time of our first visit, he was found to have bilateral and complete foot drop and weakness of the hands. Plantar and ankle reflexes were absent, but there were increased jerks at the knee, the triceps, biceps, and supinator tendons. The only sensory disturbance was a slight hypoaesthesia of the soles. Palms and soles were cold and moist. Wasting of calf muscles and muscles of the hand was considerable. There was no parotid swelling.

When last seen, on December 19, 1955, five months after the onset, his condition had changed very little, there being still no movement at all at the ankles and little in the small muscles of the hands, but power at the knee had improved. Wasting and hyperreflexia had persisted. The finger flexor test was positive at this visit.

Special Investigations.- These were as follows:-

Cholinesterase.-Tests undertaken after six weeks of illness in five patients, and after five months in three patients, showed no significant changes in true cholinesterase levels. Pseudocholinesterase was not assessed. Local difficulties prevented further tests for cholinesterase from being undertaken.

Electromyography.-Electromyography showed partial and complete reactions of degeneration. The result was shown by plotting the voltage against the duration of the electrical muscle stimulus.

Cerebrospinal Fluid.-There was a rise of protein (50-80 mg.) in three of the 10 cases in hospital. No other changes were found.

Electrocardiography.-The electrocardiogram was normal in all but three of the 10 hospital patients. In two (G. N. and R. H.) the records taken four months after onset showed inverted $\mathrm{T}$ waves in leads V4, V5, and V6. (In lead V4 the pattern was still right ventricular.) In the case of $\mathbf{R}$. H. after five months of illness, there was a normal $T$ wave in V6 and the inversion in leads V4 and V5 was less marked. The records of the third patient (M. M.) taken two weeks and six weeks after the onset of paralysis showed elevated ST segments with left ventricular pattern in leads V3, V4, V5, and V6. All three patients were comparatively well nourished. Blood pressures were respectively $180 / 100,160 / 100$, and $130 / 80 \mathrm{~mm} . \mathrm{Hg}$. There was no evidence of heart failure and the chest radiographs were normal. No evidence is adduced connecting the electro-cardiographic changes with T.O.C.P. poisoning.

Urine.-In no case did the urine contain oxalate crystals, as had been reported in the 1937-38 outbreak. Routine tests for sugar and albumin were negative in all cases.

Other Special Investigations.-The present series of patients had negative serological reactions for syphilis in the blood and the cerebrospinal fluid. Blood smears and urine analyses helped to exclude mercury, arsenic, and lead poisoning. Serological tests for viruses, including mumps, were negative. Blood counts, tests for porphyrins, and a battery of liver function tests were all within the usual limits for the local African population.

\section{Clinical Features}

The syndrome of T.O.C.P. poisoning is distinctive and in a typical case the diagnosis should be made on the clinical picture alone. 


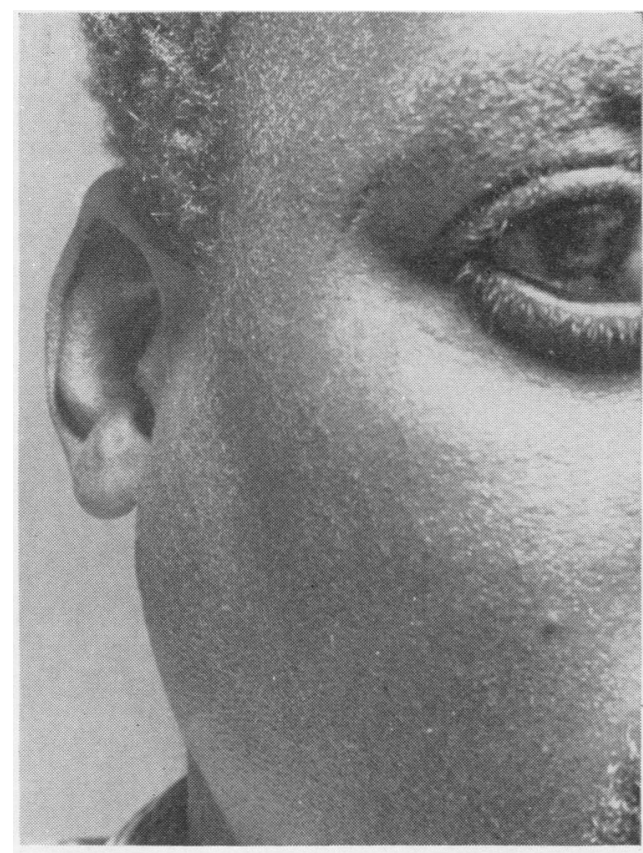

FIG. 1.-Parotid swelling two weeks after onset in A. D.

Prodromal Symptoms. - Shortly after ingestion of the poison there may be a gastro-intestinal disturbance with nausea, vomiting, and diarrhoea. This is usually transient, lasting from a few hours to a few days. The disturbance is by no means invariable; it occurred in only one case of the present series, and in three of the 16 cases of the 1937-38 Durban outbreak. It was common in some groups of the American outbreak and not in others. There, in all cases, the poison tended to be taken in large doses over a short period so that dosage is probably not related to the appearance of gastrointestinal symptoms.

Symptoms of Onset.-There follows a latent period of from three to 28 days, the duration of which is probably dependent on the size of the dose and the period of time over which it was ingested. The symptoms that follow herald the paralysis. Nearly all patients complain of sharp, cramp-like pain in the calves, and some of numbness and tingling in the feet and sometimes the hands. Within a few hours or a day or two at most these pains are followed by increasing weakness of the lower limbs and soon the patient becomes unsteady and then unable to keep his balance; if he walks it is with the stamping gait of bilateral foot drop. The cramp-like pains may cease with the

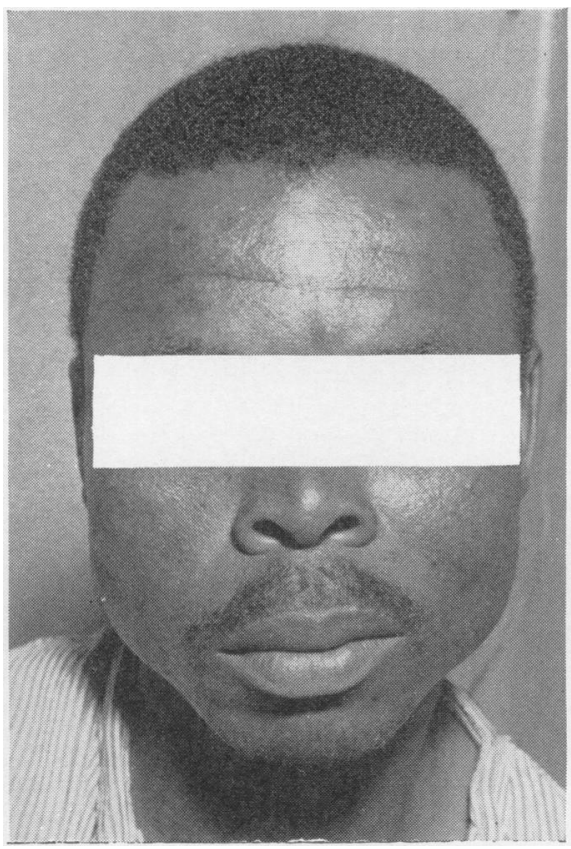

FIG. 2.-Residual parotid swelling four months after onset in $\mathbf{R}$. $\mathbf{H}$.

onset of weakness or persist for some days; in a few cases they persist for months or even years, while in others they are replaced by a dull, aching pain. In some patients, an abrupt fall to the ground, described as fainting or dizziness and probably due to weakness of the lower limbs, is the first symptom after the latent period. Cramps may or may not follow this dramatic onset. It is at this stage that the average case of moderate severity reports to the physician.

Constitutional Signs.-In Durban in 1937-38 Drummond noted a euphoria. Our patients showed perhaps unusual equability of temper in the face of severe disability. They were apyrexial and there were no other general signs, but without exception the hands and feet were cold and sweating profusely, a sign that may persist for months. Aring (1942) noted that his patients invariably had cold and cyanotic hands and feet; in our African patients the cyanosis could not be confirmed. In two patients who suffered from malnutrition and parotid swellings, the soles and palms desquamated after some weeks.

Parotid Swelling.-Of the 10 patients seen in hospital, seven had a definite diffuse, more or less symmetrical enlargement of the parotid glands 
(Fig. 1). This swelling was not tender, it was of recent origin, and gradually diminished over several weeks (Fig. 2). On palpation the swelling was firmer than that associated with malnutrition but less firm than that of mumps. Parotid enlargement is not a feature that has been observed in other outbreaks.

Motor Changes.-Usually, when first seen, the patient is considered to have symmetrical polyneuritis. He has bilateral foot drop with complete loss of power from the ankle down. Depending on the severity of the affection, he may have weakness at the knees, less at the hips, and, only in the most severe cases, weakness of the trunk. Symmetry is very close but not absolute.

The ankle jerks are absent. Knee reflexes may be normal or occasionally depressed. Sometimes, even at this early stage, they may be exaggerated, presaging the development of increased tone. Plantar reflexes are unobtainable, probably on account of the complete loss of power. They have on occasion been described as present or normal (Zeligs, 1938; Hunter et al., 1944). This is unusual and may reflect mild involvement without complete loss of power.

Sensory Loss.- Several authors state emphatically that sensory changes do not occur. Aring (1942) considers that in most cases of which he had knowledge a report of loss of sensation was a reflection of an inadequate examination. Sampson (1942) reported sensory changes although these were admittedly unobtrusive in contrast with the motor phenomena, and Burley (1932) noted especially loss of vibration sense. Reports of muscle tenderness and nerve tenderness are fairly frequent. In the present series all the patients showed sensory loss. The degree conformed roughly but not exactly to the degree of motor loss and varied in extent from merely the soles of the feet to the whole of the limbs and even the trunk. There was a similar range in the upper limbs but, as with the motor manifestations, changes tended to appear a few days later than the lower limb affection. Usually there was anaesthesia or hypoaesthesia with loss of pin-prick and temperature sense; vibration sense was sometimes affected distally. In two of the milder cases there was for the first few days, loss of position sense and Rombergism. Muscle tenderness to pressure was found in a few of our patients. However, in comparison with the motor dysfunction, the sensory changes were not prominent.

The Upper Limbs.-One or two weeks after the onset of paralysis in the lower limbs and while this

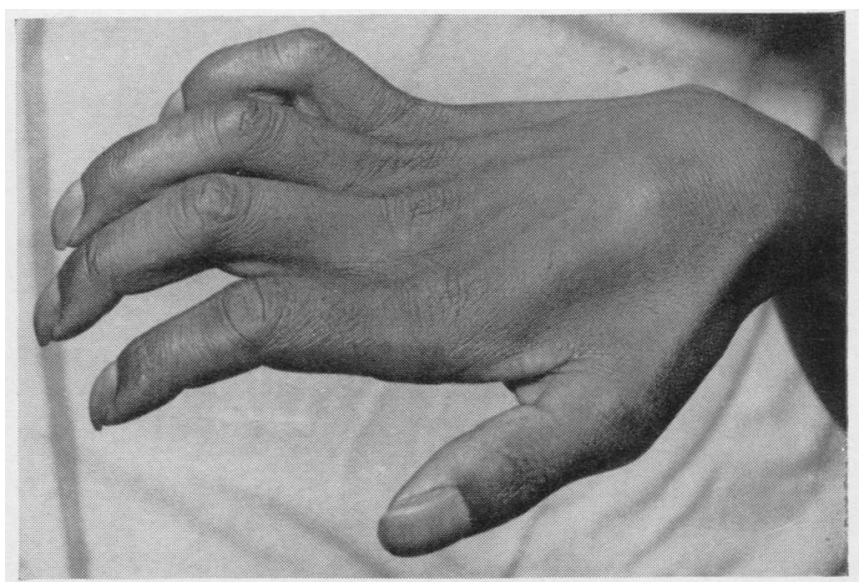

FIG. 3.-Wasting of the small muscles of the hand four months after onset, with wrist drop, in $\mathbf{R}$. $\mathbf{H}$.

paralysis may still be progressing, weakness invades the hands. Some patients show complete wrist drop and total loss of power in the hands, with weakness up to the elbows. Neither weakness above this level nor cranial nerve palsies are described except in one fatal case where the dose of T.O.C.P. was enormous. Sensory changes, usually milder than in the lower limbs, are now found in the hands.

Wasting.-About three weeks after the first paresis a most striking and rapid wasting may be observed. While the small muscles of the feet, the calves, the anterior tibials, and the thighs do not escape, in so far as they are involved in the disease, the change is most obvious in the small muscles of the hands (Fig. 3). These are symmetrically and uniformly involved as though there were a complete lesion of the ulnar and median nerves. Muscle fibrillation has been reported (Hunter et al., 1944) but was not observed in the present series.

Upper Motor Neurone Involvement.-At about this time, another diagnostic feature becomes obvious. Earlier signs may have suggested the involvement of the pyramidal tracts but this only develops definitely by about the third week or later. The knee jerks now become exaggerated and so also may the biceps, triceps, and supinator jerks. A finger flexor reflex may appear for the first time or increase. In severe cases, the signs of upper motor neurone affection are delayed, probably masked by the gross weakness. The mildest cases may not show upper motor neurone involvement at all. After six weeks these signs were not obvious in three severe cases and one mild case of the present 
series but they were evident in the other seven. As the pyramidal tract lesion develops, involuntary flexor withdrawal of the whole limb follows gentle plantar stimulation. Babinski responses are seen much later.

Earlier descriptions of T.O.C.P. poisoning have not emphasized the appearance of pyramidal tract signs within the first month. These signs are of diagnostic importance.

Regression.-The muscular weakness progresses over several weeks, sometimes even months, before it becomes stationary. Sensory changes often begin to regress in the early weeks and then power returns gradually in patients who are only mildly affected. The milder the case, the sooner sensory changes regress. Improvement begins with sensation, then power in the hands, then power in the lower limbs. Flesh slowly returns to the muscles. Improvement continues gradually over the next year or more. One of our patients who was affected in 1938 felt that he had continued to improve for about four years. In the present series, sensation had begun to improve in all cases from one week to three months after onset. Power began to return in from one to four months.

Prognosis.-Many authors state that most cases recover completely. While it is true that many are rehabilitated a large number of patients do not regain normal function of the central nervous system. Zeligs (1938), writing eight years after the United States outbreak, surveyed the records of 316 patients. He was able to follow up 60 patients, all of whom were disabled and still in institutions. Aring (1942) examined more than 100 patients in the 10 years after the same outbreak and these appear to have been still affected. Of the 80 patients in the Swiss incident, 14 were quite well after five years, 15 were totally incapacitated, and 38 showed "muscular pseudospasticity" (Walthard, 1946). Our four patients, after 18 years, all show some signs of disease. The mildest case has slight weakness at the ankles, while the most severely affected has bilateral positive Babinski reflexes with involuntary flexor withdrawal, increased tone and ankle clonus, spastic gait, foot drop, wasting, and persistent cramps. The residual signs and symptoms were entirely confined to the lower limbs, and this has also been the experience of other observers. All four patients are rehabilitated socially and economically and the two seriously disabled members of the family make light of their disabilities as they did at the onset. They are in touch with another victim of the Durban 1937-38 outbreak and report that he still has bilateral foot drop.

The patients involved in the present outbreak who were seen up to five months after onset were all still affected. There was weakness and wasting of varying degrees in the feet and the small muscles of the hands, and seven showed upper motor neurone signs.

Special Investigations.-From experimental evidence a depression of the pseudo-cholinesterase level would be expected, with a normal or moderately depressed true cholinesterase. Pseudo-cholinesterase was not measured in our series and no significant changes were found in the few assays of true cholinesterase that we were able to make.

Electromyography has shown partial and complete reactions of degeneration in all cases so far reported. It is unlikely, in view of the normal true cholinesterase levels and the clinical picture, that there is any neuro-muscular block.

Cerebrospinal fluid changes have usually been confined to a rise of protein in a few cases with occasionally a small increase in lymphocytes. Zeligs (1938) stated that only two of his 120 cases showed a rise in protein while an increase in cells was more common.

\section{Diagnosis}

The characteristic features of the illness are found, as in many other nervous diseases, in the sequence of developing lesions and in their unusual combination. The patient presents with a predominantly motor polyneuritis causing bilateral foot drop and a history of cramps in the calves for the preceding few days. The extremities are cold and sweating. Soon the lesion invades the hands; rapid and symmetrical wasting of the calf muscles and the small muscles of the hand is seen next and shortly afterwards exaggerated jerks appear at the knee and perhaps also in the upper extremities.

A diagnosis of polyneuritis may be made, especially where the protein level in the cerebrospinal fluid is raised, until the upper motor neurone lesion develops. Motor neurone disease produces the same combination of lesions (even sensory changes have been described) but the sequence of events, the rate of development of the lesion, and the progress of the wasting and its limited distribution, as well as the usual absence of muscle fibrillation, should readily exclude this disease.

Tri-ortho-cresyl phosphate is an irreversible cholinesterase inhibitor. The only other anticholinesterases known to produce a delayed paralysis are the organic phosphorus insecticides " mipafox" and, experimentally, di-isopropyl-fluorophosphonate (D.F.P.). In Germany a similar paralysis following "parathion" poisoning has been described; parathion is an organic phosphorus insecticide but 
experimentally it has failed to cause delayed paralysis. In the case of the organic phosphorus insecticides, a history of exposure generally suggests the nature of the disorder. There is in these cases also a typical history of acute cholinergic symptoms at the time of exposure, with flaccid paralysis and vomiting and diarrhoea which may be violent and sustained. While mild gastro-intestinal symptoms may occur with the ingestion of T.O.C.P. these are inconstant and not immediate. Certainly, the delayed paralysis of "mipafox" mimics that of T.O.C.P. Bidstrup, Bonnell, and Beckett (1953) show a photograph of a wasted hand with a lesion precisely similar to those found in our patients.

The effect of T.O.C.P. on pseudo-cholinesterase is marked and prolonged but true cholinesterase is not inhibited to any major degree (Earl and Thompson, 1952; Aldridge, 1954). On the other hand, " mipafox" inhibits true cholinesterase as well as pseudo-cholinesterase; reduced levels of both are found in patients with "mipafox" poisoning.

\section{Pathology and Toxicology}

The essential lesion in patients who die of T.O.C.P. poisoning in either acute or chronic phases and in animals is myelin degeneration of the peripheral nerves, the anterior nerve roots, the columns of Goll, and the lower pyramidal tracts. In animals, the spino-cerebellar tracts and the long association fibres of the anterior columns also suffer demyelination. In the acute phase there is chromatolysis of the cells of the anterior horns of the spinal cord, while in the chronic phase these cells are reduced in number (Smith et al., 1932; Aring, 1942; Goodale and Humphreys, 1931; Earl and Thompson, 1952; Aldridge, 1954).

The probable pathogenesis of the lesions is as follows:-(1) The differing immediate cholinergic effects of "mipafox", D.F.P., and " parathion", on the one hand and T.O.C.P. on the other, are due to their variable action on true cholinesterase. The former group depress cholinesterase levels and produce severe effects; T.O.C.P. does not depress the level, and symptoms are absent. (2) The paralysis which follows T.O.C.P. poisoning and may follow "mipafox" and "parathion" poisoning and can probably follow D.F.P. poisoning (as it does in hens) is directly related to demyelination. (3) The demyelination may be the result of a similar action by these poisons against an enzyme, possibly pseudo-cholinesterase or one related to it, which is concerned in the nutrition of myelin.

\section{Aetiology of the Parotid Enlargement}

The parotid swelling is a feature that has not been noted in previous outbreaks. Parotid swelling in South Africa is commonly seen in malnourished African subjects. In such cases the development is imperceptible, the swelling is soft and it does not subside rapidly. Signs of malnutrition can be found in the great majority of urban African location dwellers. In this group of seven patients with the parotid swelling of T.O.C.P. poisoning, five showed mild, i.e., average, malnutrition, one was distinctly malnourished (and alcoholic), and one was clinically well nourished (and an abstainer.) The three children were all mildly malnourished and all affected. The recent origin and steady subsidence of the parotid swellings in our cases of T.O.C.P. poisoning excluded malnutrition as a prime cause. Both clinically and serologically mumps was excluded as a cause. Arsenic trioxide, botulism, iodides, lead, and sulphuric acid (Von Oettingen, 1952) were unlikely to be the cause.

A possible relationship with the parotid swelling found in malnutrition is suggested by the fact that pseudo-cholinesterase levels are depressed in human malnutrition as well as in T.O.C.P. poisoning (Hutchinson, McCance, and Widdowson, 1951). Another possibly related finding was that the essential histological changes in rats following chronic "parathion" poisoning included changes in the salivary glands. Perhaps T.O.C.P. has an effect on the salivary glands which only becomes manifest in a gland already suffering from nutritional deficiency. The absence of such swellings in other outbreaks is difficult to explain, as is also the limited distribution of parotid swellings in malnutrition.

\section{Treatment}

No known treatment has any specific effect and measures are limited to the necessary physical and moral support. Bidstrup, et al. (1953) found that early activity in delayed " mipafox" paralysis, while cholinesterase was still depressed, caused spasms and twitching. No such effect was observed in the present series in spite of early activity. Only one patient complained of ready fatiguability. The impression in previous outbreaks was that those who tried hardest and were most active did best, but the most severely affected may have been too grossly impeded to try. The present series has not been long enough under observation to discuss this further. The family poisoned in Durban in 1937-38 all believe that the severe effects persisting in the father and daughter were due to their uncurbed activity in the early stages, while the mother and son, who have escaped very lightly, carefully obeyed medical injunctions to remain at rest. 
Summary

An outbreak of T.O.C.P. poisoning in 11 African patients in Durban, South Africa, in 1955, is described.

The mode of poisoning is discussed and from the epidemiology of this outbreak it is suggested that water, as well as the previously reported solvents such as lipids and alcohol, may be a vehicle for the poison, either in solution or suspension or both.

This is the first outbreak to be reported in relation to the industrial use of T.O.C.P. as a plasticizer; the necessity for precautions in industry is stressed.

Family and social and occupational factors are shown to be important in diagnosis.

The clinical picture, which includes a delayed flaccid paralysis with subsequent upper motor neurone signs, is emphasized as an important and reliable guide to diagnosis. The pathology and aetiology of the nervous lesions are discussed.

Swelling of the parotid glands is reported in this outbreak for the first time.

A follow-up after 18 years on four patients poisoned in 1937-38 shows that disability may be profound and permanent.

Our thanks are due to Dr. J. Drummond for his help and for his data from the previous Durban epidemic; to Dr. Donald Hunter for his advice on the manuscript; to Dr. S. Disler, Medical Superintendent of the King Edward VIII Hospital, for permission to publish, and to Dr. D. Pooler, Dr. F. Davidson, Dr. K. Drummond, and Professor B. Adams for giving us access to their patients. We are grateful to the staff of the Durban City Health Department for their assistance in following the investigation to the homes of the patients and to the factory. We are indebted to Dr. M. K. S. Hathorn for the photographs.

\section{REFERENCES}

Aldridge, W. N. (1954). Ibid., 56, 185

Aring, C. D. (1942). Brain, 65, 34.

Barns, J. M., and Denz, F. A. (1953). J. Path. Bact., 65, 597.

Bidstrup, P. L., Bonnell, J. A., and Beckett, A. G. (1953). Brit. med. J., 1, 1068 .

Burley, B. T. (1930). New Engl. J. Med., 202, 1139.

(1932). J. Amer. med. Ass., 98, 298.

Drummond, J. (1938). Personal communication.

Earl, C. J., and Thompson, R. H. S. (1952). Brit. J. Pharmacol., 7, 26 I, 685 .

Goodale, R. H., and Humphreys, M. B. (1931). J. Amer. med. Ass.,

Hodge, H. . C.., and Sterner, J. H. (1943). J. Pharmacol., 79, 225.

Holmstedt, B. (1954). Pharmacol. Rev., 6, 49.

Hotston, R. D. (1946). Lancet, 1, 207.

Humpe, F. (1942). Munch. med. Wschr., 89, 448. Quoted by Hunter, D. (1955).

Hunter, D., Perry, K. M. A., and Evans, R. B. (1944). British Journal of Industrial Medicine, 1, 227.

Hutchinson, A. O., McCance, R. A., and Widdowson, E. M. (1951) Spec. Rep. Ser. med. Red. Coun. (Lond.), No. 275, p. 216.

Lorot, C. (1899). Les combinaisons de la créosote dans le traitement de la tuberculose pulmonaire. These de Paris No. 25. Quoted de la tuberculose pulm

Sampson, B. F. (1942). S. Afr. med. J., 16, 1.

Sampson, B. F. (1942). S. Afr. med. J., 16, 1. . F. (1932). Nat. Inst. M.ith Bull., No. E. 160 , p. 1 . Hith Bull., No. 160, p. 1.
and Elvove, E. (1931). Publ. Hlth Rep. (Wash.), 46, 1227.

-, and Elvove, E. (1931). Publ. Hlth Rep. (15, 2509.

Ter Braak, J. W. G. (1931). Ned. T. Geneesk., 75, 2329.

Von Oettingen, W. F. (1952). Poisoning. Hoeber, New York. Walthard, K. M. (1946). Schweiz. Arch. Neurol. Psychiat., 58, 189. Quoted by Hunter, D. (1955)

Zeligs, M. A. (1938). J. nerv. ment. Dis., 87, 464. 